\section{Re: Home Visits and the Social Context}

To the Editor: The article by Peterson and colleagues ${ }^{1}$ and commentary by Hamrick ${ }^{2}$ outline the "shape" of physician house calls at this point in time, and Hamrick raises compelling reasons to broaden the practice, particularly in the coming era of health care reform. House calls make sense for any number of economic and quality of care reasons. But house calls also make sense in helping to remedy the social ignorance of physicians about the lives of our patients. Physicians, who predominately come from one social class, ${ }^{3}$ need to learn how our patients who struggle with financial and social as well as medical obstacles live their lives.

When I visited Japan this year and learned that Japanese general practitioners spend up to a third of their daily visits as home visits, I was, to be honest, surprised. When I told the Japanese residents whom I was teaching that American Academy of Family Physicians data show that U.S. family doctors do, on average, less than one house call per week, they expressed amazement. They asked me, "How do you know anything about your patients' lives if you don't make house calls?" How, indeed? The answer is that we don't, or that we understand our patients only in the context of offices and hospitals where we arrange the pictures, we set up the furniture, we stock the fridge, and we feel powerful and comfortable.

Real patient- and family-centered care requires understanding the context of our patients' lives on our patients' terms. To do this, we need to demand organizational and payment reforms that are necessary to help us bring that context into our care. We also need to demand that any "new models" of primary care graduate education require substantial, not token, involvement with our patients in the community where they live. House calls may also teach us necessary humility about how our office admonitions relate to the complex, rich, and eventful lives our patients live in their "real world," not our office examining rooms.

John J. Frey, III, MD

Department of Family Medicine

University of Wisconsin, Madison

jfrey@fammed.wisc.edu

\section{References}

1. Peterson LE, Landers SH, Bazemore A. Trends in physician house calls to Medicare beneficiaries. J Am Board Fam Med 2012;25:862-8.

2. Hamrick I. More house calls by fewer physicians. J Am Board Fam Med 2012;25:759-60.
3. Jolly P. Analysis in brief. Diversity of US medical students by parental income. Washington, DC: Association of American Medical Colleges; 2008. Available from https://www.aamc. org/ download/102338/data/aibvol8no1.pdf. Accessed March 11, 2013.

doi: 10.3122/jabfm.2013.03.120328

The above letter was referred to the authors of the article in question, who offers the following reply.

\section{Response: Re: Home Visits and the Social Context}

To the Editor: Dr. Frey's ${ }^{1}$ excellent comment adds an additional argument for house calls. How can we know our patients if we do not know their life circumstances? House calls are a great opportunity to teach our residents cultural competence by immersing them into the culture of their patients and community. House calls are far more commonplace in other cultures and countries. In Japan, as well as in France, house calls are legally required of physicians. In my native Germany, house calls to patients with limited mobility are legally required of primary care and specialist physicians. $^{2}$ All these countries rank higher than the United States in quality of medical care, and their populations have greater longevity. ${ }^{3}$ As outlined in the commentary, ${ }^{4}$ the evidence supports house calls for reducing hospital readmissions, length of stay, nursing home placement, functional decline, and mortality. House calls may just be the key to improving our quality of care.

Irene Hamrick, MD

Department of Family Medicine University of Wisconsin

Madison, WI

ihamrick@wisc.edu

\section{References}

1. Frey JJ. Re: Trends in physician house calls to Medicare beneficiaries. J Am Board Fam Med 2013;26:339.

2. Christoph J. Patient bittet um Hausbesuch, im Zweifel immer fahren. Der Allgemeinarzt 2008;14:26-7.

3. World Health Organization. The World Health Report 2000. Health systems: improving performance. Geneva: WHO; 2000. Available from http://www.who.int/whr/2000/en/. Accessed March 11, 2013.

4. Hamrick I. More house calls by fewer physicians. J Am Board Fam Med 2012;25:759-60.

doi: 10.3122/jabfm.2013.03.130056

\section{Response: Re: Home Visits and the Social Context}

To the Editor: We read with great interest the letter by Dr. Frey ${ }^{1}$ who states that house calls help to "remedy the 
social ignorance of physicians about the lived lives of our patients." We could not agree more. Part of the inspiration for our study was one of the authors (LP) taking a house call elective as a medical student with the other author (SL). During the elective we traveled to neighborhoods both poor and rich, to homes with well-manicured yards, and to those with refuse lying around. Every doorway we crossed offered new insights into the lives of our patients and, as Ian McWhinney ${ }^{2}$ so eloquently stated, "we could see the history and dreams of our patients on the walls". We witnessed the struggles of both the patients and their family members to achieve the best care they could in their situation. In some houses the pill box was easily located, schedules of home health nursing and physical therapy appointments were available, food was in the refrigerator, the house was clean. In others, medications were disorganized, with empty bottles begging to be refilled, and urine stains were evident on the couch from when the patient did not have help to get up. The Japanese residents mentioned by Dr. Frey were correct in saying that a physician can never truly understand their patient's lives unless they make house calls. As family physicians wrestle with practice transformation and ascending the levels of the patient-centered medical home, we hope more physicians take the ultimate patient-centered step by driving to their patient's home to better understand and contextualize the lives and choices faced by our patients.

Lars Peterson, MD, PhD American Board of Family Medicine Lexington, KY lpeterson@theabfm.org Steven Landers, MD, MPH VNA Health Group Red Bank, NJ

\section{References}

1. Frey JJ. Re: home visits and the social context. J Am Board Fam Med 2013;26:339.

2. McWhinney IR. Fourth annual Nicholas J. Pisacano Lecture. The doctor, the patient, and the home: returning to our roots. J Am Board Fam Pract 1997;10:430-5.

doi: 10.3122/jabfm.2013.03.130085

\section{Re: The Impact of Prior Authorization Requirements on Primary Care Physicians' Offices: Report of Two Parallel Network Studies}

To the Editor: Morley et al $^{1}$ report on practice cost estimates per full-time-equivalent physician for prior authorizations in 2 Northeastern markets, noting that their results vary considerably from previous publications. Across different markets there is substantial variation in the availability and uptake of technology to facilitate this process (eg, multipayer physician/practice web-based portals providing immediate access to patient eligibility, benefits, and engines that automatically approve authorization requests). The authors collected detailed data on the workforce resources (people) expended by the practices, but did not comment on the processes used at those sites as a possible explanation for the seemingly dramatically improved efficiency compared with earlier studies.

Katherine A. Schneider, MD

Medecision

Wayne, PA

katherine.schneider@medecision.com

\section{Reference}

1. Morley CP, Badolato DJ, Hickner J, Epling JW. The impact of prior authorization requirements on primary care physicians' offices: report of two parallel network studies. J Am Board Fam Med 2013;26:93-5.

doi: $10.3122 / j a b f m .2013 .03 .130063$

The above letter was referred to the author of the article in question, who offers the following reply.

\section{Response: Re: The Impact of Prior Authorization Requirements on Primary Care Physicians' Offices: Report of Two Parallel Network Studies}

To the Editor: In the letter regarding our study of prior authorization costs, ${ }^{1}$ Schneider ${ }^{2}$ describes a "seemingly dramatically improved efficiency compared with earlier studies." This is an incorrect reading of our results. We do not believe that our report describes an improvement in efficiency over earlier estimates. Rather, it estimates costs using an entirely different method than previous studies and comes up with different results. It is our feeling that the studies we cited-by Casalino et $\mathrm{al},{ }^{3}$ Morra et al, ${ }^{4}$ and Sakowski et $\mathrm{al}^{5}$-represent the high end of a range of possible estimates and that our studies represent the low end. True costs are probably somewhere in the middle and are certainly dependent on the context, as Schneider points out.

Regarding processes that may have affected cost outcomes, we currently are analyzing the existing data set using inferential statistical techniques. There are early suggestions that practice characteristics (particularly the use of electronic health records) might play a role. However, the exact mechanisms and relationships between processes and costs are by no means certain. We hope to describe results from our secondary analyses in a future report. Regardless of what we find, a much larger study than ours would be required to answer definitively questions about the effects of particular processes on prior authorization costs.

Christopher P. Morley, PhD

Department of Family Medicine

Department of Public Health \& Preventive Medicine Department of Psychiatry \& Behavioral Sciences SUNY Upstate Medical University Syracuse, NY morleycp@upstate.edu 